\title{
Non-Axial Crushing of E-Glass/Polyester Pultruded Tubes
}

\author{
MichaEl J. CZAPliCKI AND RichaRd E. RoBERTSON \\ University of Michigan \\ Department of Materials Science and Engineering \\ Ann Arbor, MI 48109-2136
}

PETER H. THORNTON

Materials Science Department

Ford Motor Company

Dearborn, MI 48I21-2053

(Received September 18, 1989)

(Revised Janaury 8, 1990)

\begin{abstract}
Two types of non-axial crushing, off-axis crushing and angled crushing. have been identified and significant differences found between the E-glass/polyester pultruded tubes crushed in these different configurations. Energy absorption for the two types of crushing was found also to vary significantly with the angle of inclination, with the difference being largest at high angles of inclination. Reasons for energy absorption differences between the crushing configurations include the initiation of different crack patterns, different loading of individual fibers, and altered friction. For all angles, the load required for continued crushing was found to fluctuate more for off-axis crushing than for angled crushing.
\end{abstract}

\section{INTRODUCTION}

CRASHWORTHINESS HAS LONG been an important consideration for passenger vehicles. A vehicle is made crashworthy by incorporating into it a structure that deforms in collisions at or below a critical stress level in a way so as to absorb energy. There is a considerable interest currently in the use of polymer composite materials in crash energy absorbing structures [1-3]. The primary reasons for this are the high energy absorption per unit weight [4], and the predictable crushing behavior of these structures. In addition, composites damp vibrations well [5] and allow for reduction in the number of parts used per structure [6]. In axial impact, polymer composite structures can be made to fail by a progressive fracture process that absorbs much energy. A collision is considered axial when a vehicle impacts a surface normal to its longitudinal axis. Most collisions, however, deviate somewhat from axial loading. Since constant cross- 
section metal tubes are known to fail in bending under non-axial loading [7], there is concern that polymer composites may show similar behavior. Also unknown is whether the attractive type of crush behavior exhibited for axial loading can be reproduced for non-axial loading. This paper addresses these concerns by examining the two types of non-axial loading encountered in a vehicle collision: off-axis loading and angled loading.

Angled loading occurs when a vehicle moving forward along its longitudinal axis impacts an object tilted away from being perpendicular to the vehicle's longitudinal axis. Off-axis loading occurs when a spinning vhicle impacts an object from a direction not along its longitudinal axis. To evaluate the two loading conditions, E-glass/polyester pultruded tubes were tested under loading geometries that approximate these two types of collisions. The crushing behavior was examined to determine if non-axial loading produces changes from axial loading. Of primary interest is the behavior of the crush zone and the global structural stability of the tube. The crush zone is the small region of material actively being crushed at any instant. The size, crushing resistance, and stability of the crush zone are the factors most responsible for the magnitude of energy absorption obtained [8].

For crushing to proceed in a satisfactory manner, crush zone and global structural stability both must be maintained. Crush zone stability implies that the crushing proceeds in a stable controlled manner for the entire crush distance. Structural stability implies that the structure does not fail in bending or by Euler buckling. If these two conditions are satisfied, fibrous polymer composites can be good energy absorbers.

\section{EXPERIMENTAL}

All specimens tested were identical except for specimen length. The tubes had a square cross-section with a 2 in. outside diameter and $1 / 8$ in. wall thickness. The length of the specimens varied from $4.5 \mathrm{in}$. to $10 \mathrm{in}$., depending on the angle of inclination used for the test. Shorter specimens had to be used at higher angles. Specimen length is believed not to affect the crushing process. But to obtain the most representative results, the use of the longest specimen practical is desired. All tubes were triggered with a $45^{\circ}$ bevel as shown schematically in Figure 1. A trigger is a stress concentrator from which crushing initiates. The bevel trigger used for this study was produced by grinding a $45^{\circ}$ slope on each of the four tube sides at one of the tube's ends. A bevel was used in preference to other triggers that might have produced higher energy absorption levels because of its geometric simplicity and the ease of fabrication.

The E-glass/polyester tubes used were made by pultrusion. The tubes had a nominal glass content of $52 \%$ by weight. The glass reinforcement consisted of continuous uniaxial fiber bundles in the tube wall center and continuous random fibers on each of the tube surfaces as shown in Figure 2. The tubes had a square cross-section and were about $51 \mathrm{~mm}$ across. Each wall had a thickness of 3.2 $\mathrm{mm}$. The portion of the wall containing fiber bundles was about $1.5 \mathrm{~mm}$ and the glass plies about $0.9 \mathrm{~mm}$. About $60 \%$ of the total glass was from the uniaxial 


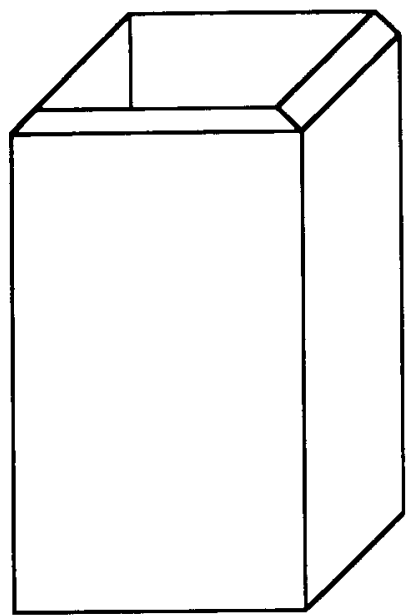

Figure 1. Schematic of bevel triggered tube.

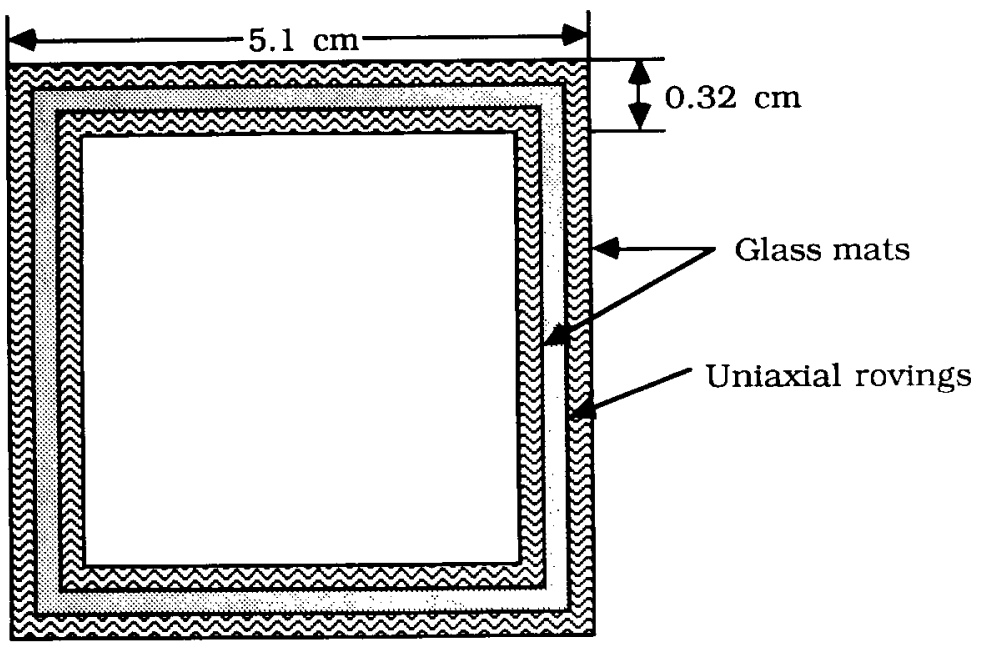

Figure 2. Schematic of tube cross-section. 


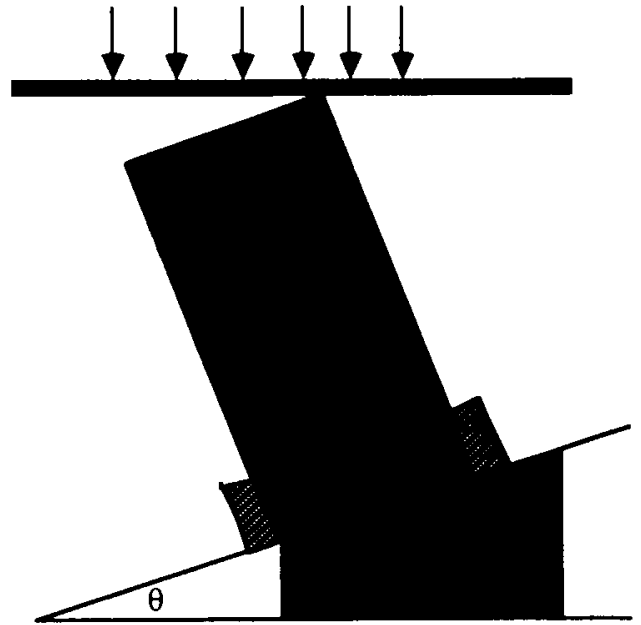

Figure 3. Off-axis loading test set-up.

rovings and $40 \%$ from the random fibers. Pultrusions are produced by pulling continuous glass fibers through a resin bath and then around a mandrel and through a heated die to produce tubes of constant cross-section. The tubes are cut to various lengths after cooling. During pultrusion, the tube surfaces may be wrapped with glass fabrics to produce a product with improved lateral support and this was done for the specimens used in this study.

The two non-axial loading conditions used, off-axis loading and angled loading, are shown in Figures 3 and 4 before crushing begins. A simplified loading diagram for steady state crushing in shown in Figure 5 to help demonstrate the

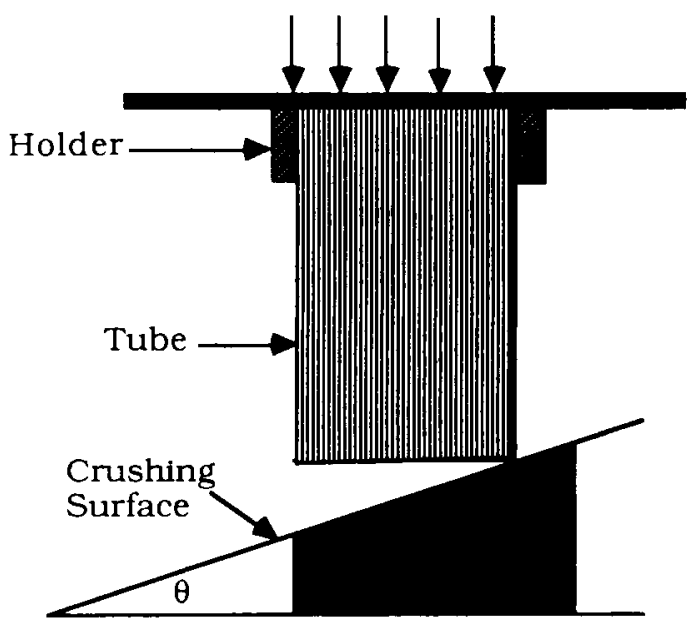

Figure 4. Angled loading test set-up. 


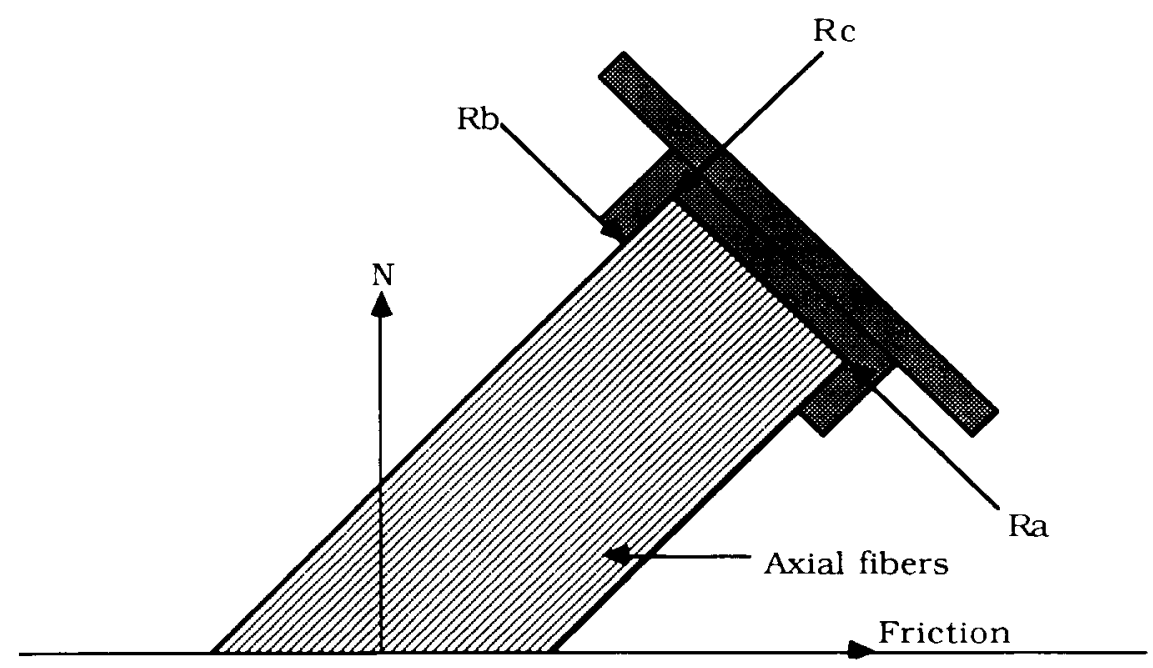

Figure 5. Resolved loading for non-axial loading.

mechanical inequality between off-axis and angled loading. Although the two conditions may seem mechanically equivalent from Figures 3 and 4 , this would be true only if the crushing plate were frictionless. However, friction is not zero and cannot be approximated as zero during crushing. The frictional force $F$ can be written as the product of the coefficient of friction $\mu$ and the applied normal force $N$ :

$$
F=\mu N
$$

The difference in friction arises because the crushing plate moves laterally with respect to the tube in off-axis loading, which produces a dynamic type of friction. The tube has no relative lateral motion in angled loading, producing no lateral movement of fibers and thus is a static type of friction. Since static friction is greater than dynamic friction, a difference between the two loading conditions results. Therefore, the two loading conditions must be examined separately.

A frictional force is the product of the coefficient of friction and the applied normal force if there is movement between two bodies.

Specimens were tested in the two loading configurations by crushing with a $20,000 \mathrm{lb}$ load capacity Instron machine at a speed of $0.5 \mathrm{in} / \mathrm{min}$. For both loading conditions, tubes were tested from $10^{\circ}$ to $30^{\circ}$ in increments of $5^{\circ}$. Testing was not possible at $5^{\circ}$ because of limitations of the loading fixture. All specimens were crushed into a flat piece of 0.1 in. thick 1010 steel, backed by a rigid plate. The mean load, specific energy absorption, and the load-displacement curve were recorded for each test. Failure mode differences were observed for each of the loading conditions. 


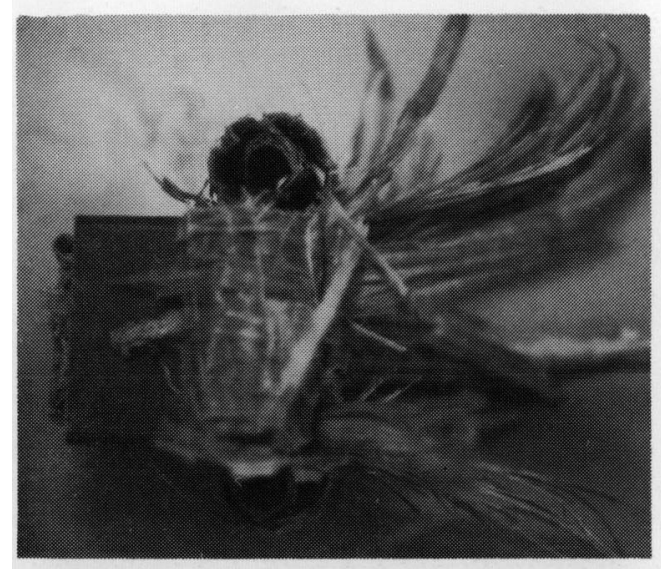

Figure 6. Photograph of crushed test specimen.

\section{RESULTS}

\subsection{Axial Crushing}

Before beginning non-axial testing, specimens were crushed axially to establish a baseline for later comparison with non-axial behavior. In axial crush, failure is initiated by pushing a loading plate against the sharp edges of the bevel trigger. The edges are crushed down, which results in cracking and delamination. Numerous cracks parallel with the unidirectional fiber bundles, and at various angles with respect to the wall surface are initiated in the body of each of the walls. These cracks are not visible during crushing and do not penetrate deeply, remaining confined to a narrow band approximately $1 \mathrm{~cm}$ below the crushing surface. Other, deeper cracks $(1-2 \mathrm{~cm})$ penetrate between the glass mat and roving interface parallel with the wall surface. These cracks produce delamination betrieen the core containing the uniaxial fibers and the surface glass mats. The depth of crack penetration resulting from crushing defines the size of the crush zone. The cracks that are most apparent during crushing are the cracks that produce delamination between the uniaxial fibers and the glass mats and can be observed at the tube corners.

During crushing, the material of each wall splays to both sides but the material does not necessarily splay evenly to the inside and outside of the tube. When crushing is initiated by a bevel trigger and the tube crushed into a flat plate, some liaterial becomes compacted and adheres to the crushing surface. The presence of this compacted material prevents fibers from contacting the plate at the geometric center of the thickness section of the tube wall. Therefore, fibers are forced to splay to one side or the other of the compacted material before contacting the crushing platen. The result is that newly crushed material appears to flow outward and then roll up on the outside of the wall (Figure 6). 
A noticeable feature of crushing is the formation of fracture lines that run across the entire width of each wall segment and approximately normal to the tube axis. Figure 7 shows a tube that has been axially crushed and sectioned along its longitudinal axis. The fracture lines can be seen edge on. The distance between the fracture lines appear to depend on the depth of delamination between the surface glass mats and central uniaxial fiber bundles. For the specimens tested in axial crushing, the distance between fracture lines ranged from 6 to 10 $\mathrm{mm}$, with a mean distance of $7.2 \mathrm{~mm}$ with a standard deviation of $0.6 \mathrm{~mm}$. As can be seen in Figure 7, the fracture lines exist in the material that is splayed to both the inside and outside of the tube.

When a load is first applied, cracks form at each of the four tube corners and propagate downward along the tube axis. After running a short distance, the cracks generally stop. For the tubes used in this experiment, the first cracks initiated stopped about $6-10 \mathrm{~mm}$ from the end of the tube that was being crushed. With crack growth stopped, the moving crush platen approached the stationary crack tips. As the platen approximately reached the crack tips, the wall segments bent back and created a fracture line in the peeled mat. After creating the fracture line, cracks again ran another $7 \mathrm{~mm}$ or so and stopped. The moving platen again approached the crack tips, creating another set of fracture lines, and the process occurs repeatedly for the entire crush length.

The crack propagation pattern at the tube corners corresponds roughly to events on the load-displacement curve. Prior to the initiation of the first cracks at the tube corners (initial delamination), the load climbs to a peak. The load then falls as the cracks penetrate to their greatest distance. With the cracks stationary. the load gradually rises as the crushing plate approaches the stationary crack tips. The load reaches a peak again just as a new fracture band forms and cracks again run along the tube corners. The occurrence of this behavior is indicated schematically on the load-displacement curve shown in Figure 8 . The formation of fracture lines is clearly seen when a load is first applied to the tube. The first set

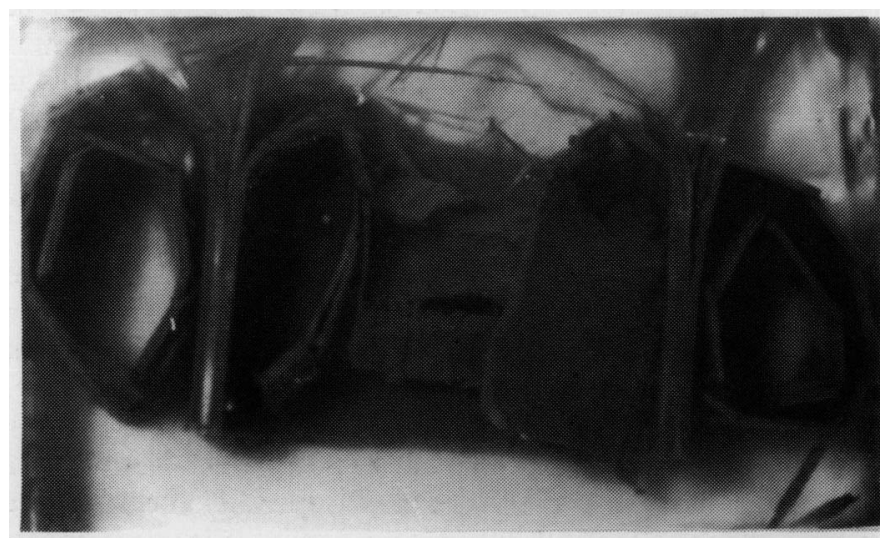

Figure 7. Photograph of longitudinal cross-section of a crushed specimen. 


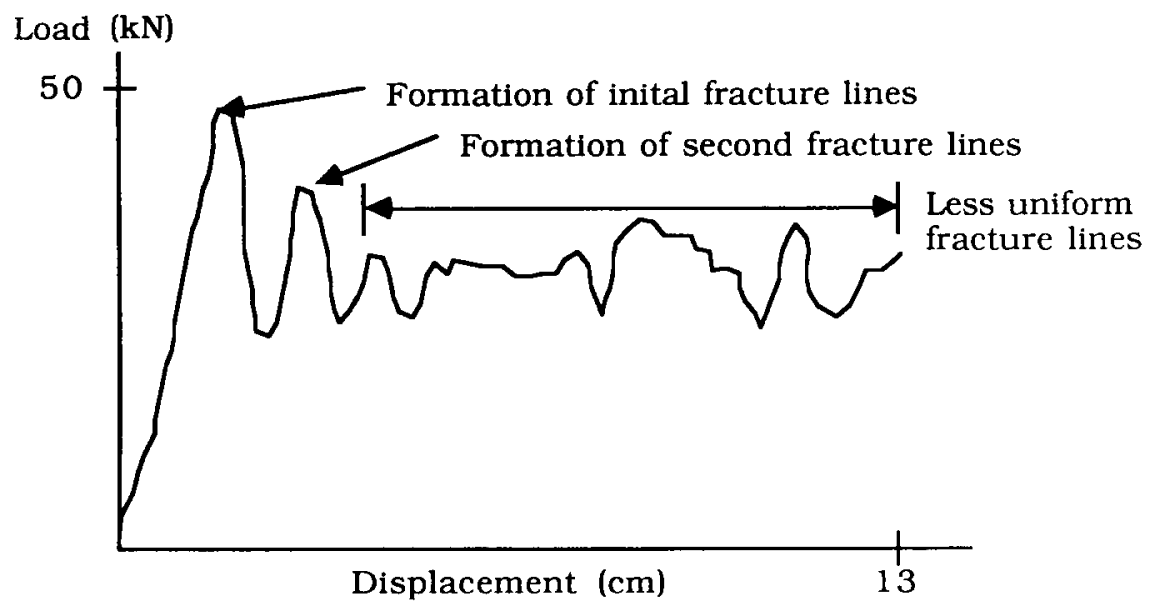

Figure 8. Load-displacement curve for axial crush test.

of fracture lines is created almost simultaneously on each the four tube walls. Also, the initiation of the first four cracks produce the largest load reduction since their formation is completely coincident. Subsequent fracture lines are not as regular and the load reductions corresponding to cracking are not so large since the formation of fracture lines seldom occurs for the four corners simultaneously. The pattern, however, is still identifiable for the entire crush distance.

Microscopic examination showed that the material between the fracture lines consisted almost exclusively of material from the glass mat layers. Although the uniaxial fiber bundles did splay to either the inside or the outside surface during crushing, most of this portion of the tube section did not fracture or become part of the layer that rolled up on either surface. Instead, on releasing the load, the unbroken fibers relaxed and exhibited their continuity by splaying upward. Because of the deep penetration of the cracks between the glass mats and uniaxial fibers, the uniaxial fibers avoided fracture largely because the radius of curvature into which the fibers were bent was large. Conversely, most of the glass mat was fractured at the fracture lines. A small number of fibers in the mats on the compressive side remained unfractured, indicating that the glass mats had failed by tension. Between the fracture lines, the glass mats were almost completely unfractured. Thus, other than the cracks at the corners, most of the cracks along the tube axis existed among the unidirectional fibers. The transverse cracks were primarily limited to the glass mats. Most uniaxial fibers that did break became part of the debris produced during crushing.

The debris constituted a small part of the volume of the crushed tube, most typically $10 \mathrm{~g}$ of debris was created in crushing a $140 \mathrm{~g}, 5 \mathrm{in}$. tube axially. The debris created from crushing polyester pultrusions consists of resin dust, clumps of fiber bundles, and a small number of individual broken fibers. In this analysis, only material that is completely broken away from the tube is classified as debris. 
An average load of about 5500 lbs was obtained for axial crushing of polyester tubes with a bevel trigger. This corresponds to a specific energy absorption (energy absorbed per unit weight) of about $24 \mathrm{~kJ} / \mathrm{kg}$.

\subsection{Non-Axial Loading}

A graph of mean crush load vs. angle of inclination for angled and off-axis loading for angles of inclination between $10^{\circ}$ and $30^{\circ}$ at $5^{\circ}$ increments is shown in Figure 9. The graph shows mean load values for off-axis and angled crushing to be similar at $10^{\circ}$ but to diverge as the angle of inclination increases and differ significantly at higher angles of inclination, such as $25^{\circ}$ and $30^{\circ}$. Although mean crush load values were noticeably different for specimens crushed in off-axis loading as compared to angled loading, morphological differences between specimens crushed in the two loading configurations were more subtle. In addition, because the crush morphology changes greatly for each type as the angle of inclination is changed, it was difficult to identify continuing morphological differences between specimens crushed by the two loading configurations over the range of crushing angles from $10^{\circ}$ to $30^{\circ}$. Since each of the tube walls is loaded differently, the corresponding crush behavior of each of the walls is also different. For this reason, each of the tube walls is referred to by number as illustrated in Figure 10.

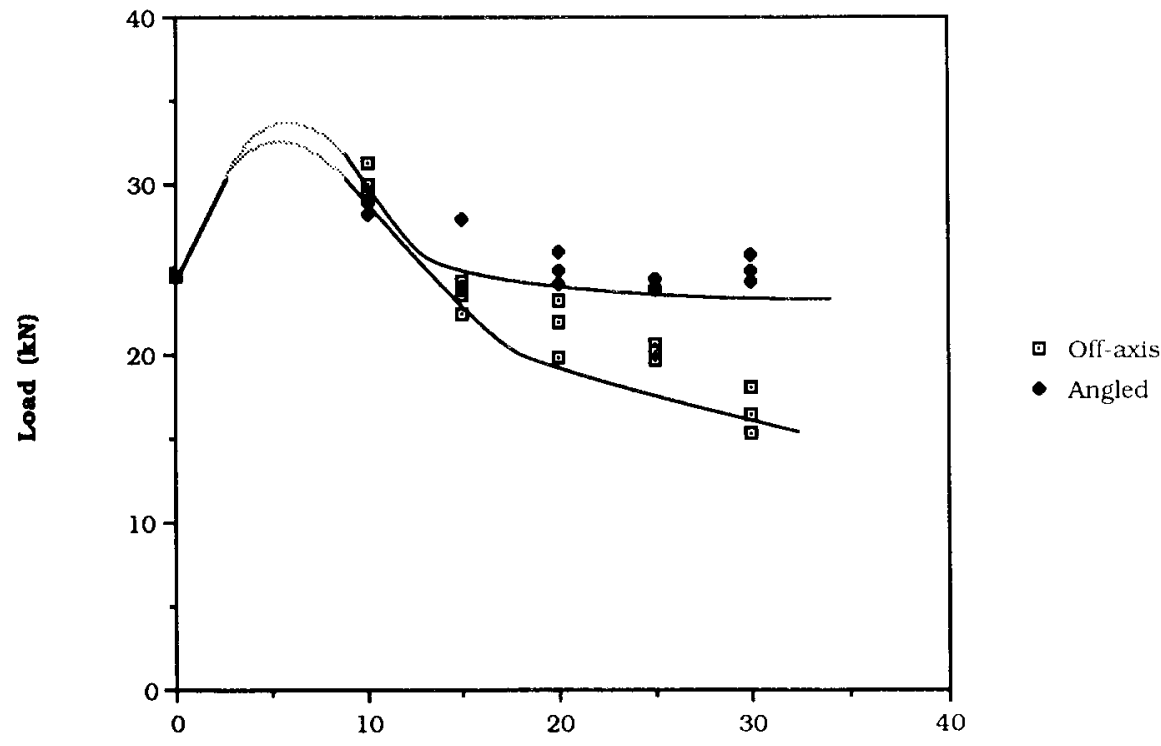

\section{Angle (Degrees)}

Figure 9. Average load vs. angle of inclination for non-axial loading. 


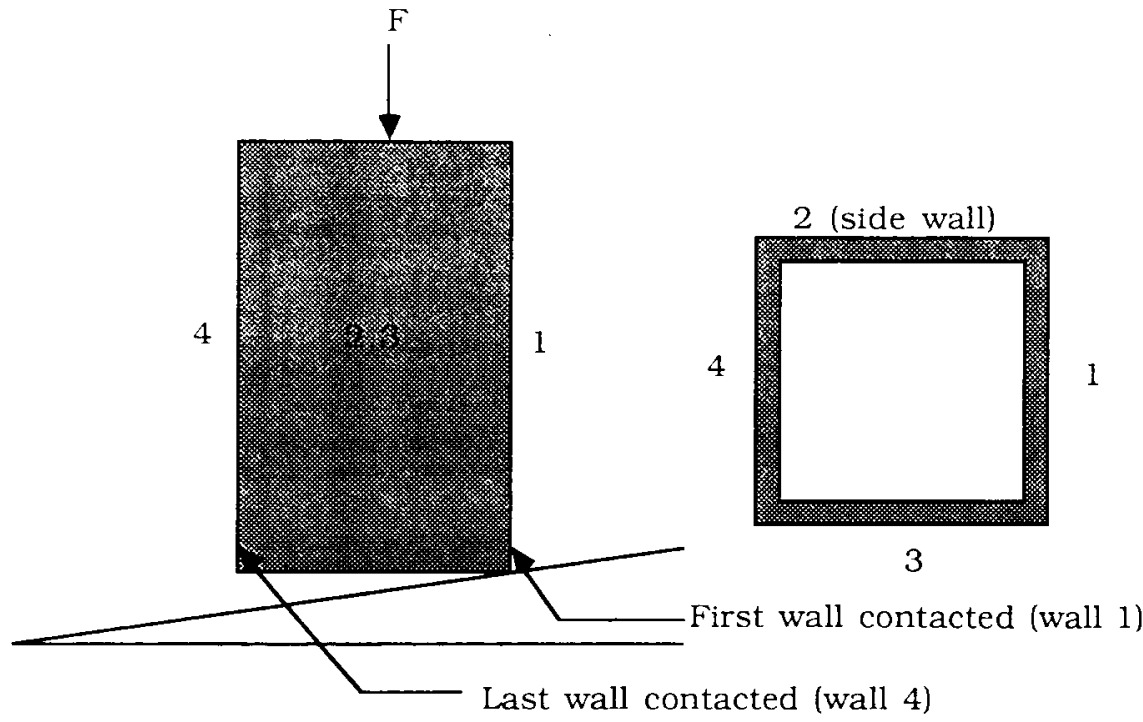

Figure 10. Diagram of wall numbering pattern.

Although crushing behavior for each of the two loading configurations changed greatly as the angle of inclination was varied, two distinct differences between the two types of loading existed for the entire range of inclination angles tested. First, the material of walls 2 and 3 generally splayed more evenly about the wall center for angled loading and preferentially to the outside surface in off-axis loading for all angles. This difference is shown in Figure 11 for several angles of inclination. Second, the fracture lines were more closely spaced for angled loading than for off-axis loading at each angle of inclination tested. This can be seen qualitatively in Figure 11. As stated previously, other differences in crush morphology for offaxis and angle loaded specimens are generally confined to specific angles of inclination and thus the two types of loading are further compared in that way.

\subsection{1 $10^{\circ}$ Crushing}

At $10^{\circ}$, the most distinct difference between angled and off-axis loading is the extent of fracture that occurs in wall 4 . In angled loading. wall 4 does not fracture and "roll up" in the way that is seen in axial loading and for walls 2 and 3. Instead, wall 4 peels back when contact with the platen is made, resulting in little damage to that wall (Figure 12). In off-axis loading. wall 4 fails in the way that is characteristic of axial loading, with the creation of distinct fracture lines. However, unlike axial loading, material splays only to the outside of the tube. Figure 13 shows a longitudinal section of a specimen crushed by off-axis loading at $10^{\circ}$. The other discernible difference between specimens crushed at $10^{\circ}$ is the distance between fracture lines for walls 2 and 3 , which averaged $6.1 \mathrm{~mm}$ for angled loading and $7.0 \mathrm{~mm}$ for off-axis loading. Load-displacement curves (Figure 14) for the 


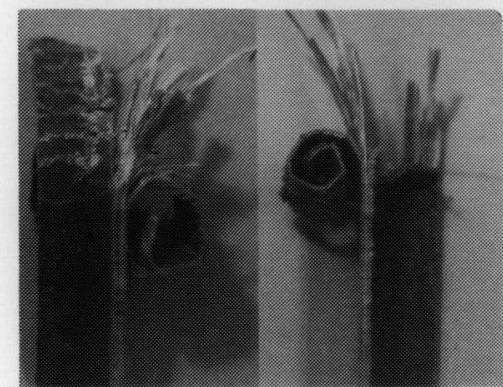

a) $10^{\circ}$

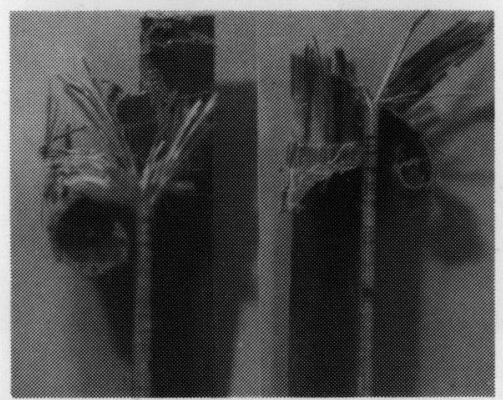

c) $20^{\circ}$

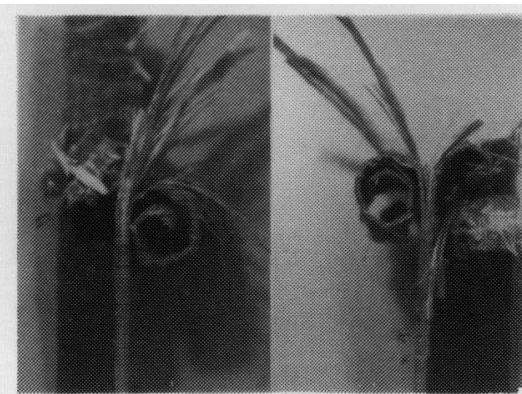

b) $15^{\circ}$

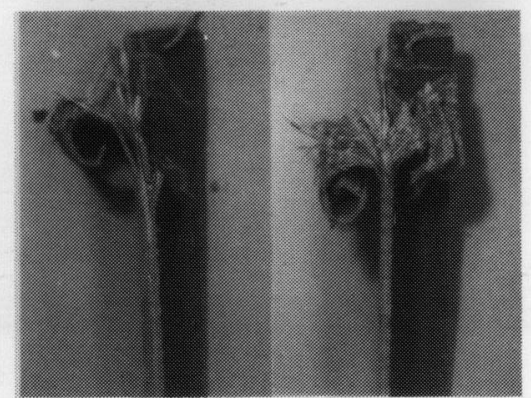

d) $25^{\circ}$

Figure 11. Longitudinal cross-section showing walls 2 and 3 for specimens crushed at different angles of inclination, off-axis on left for a-d.

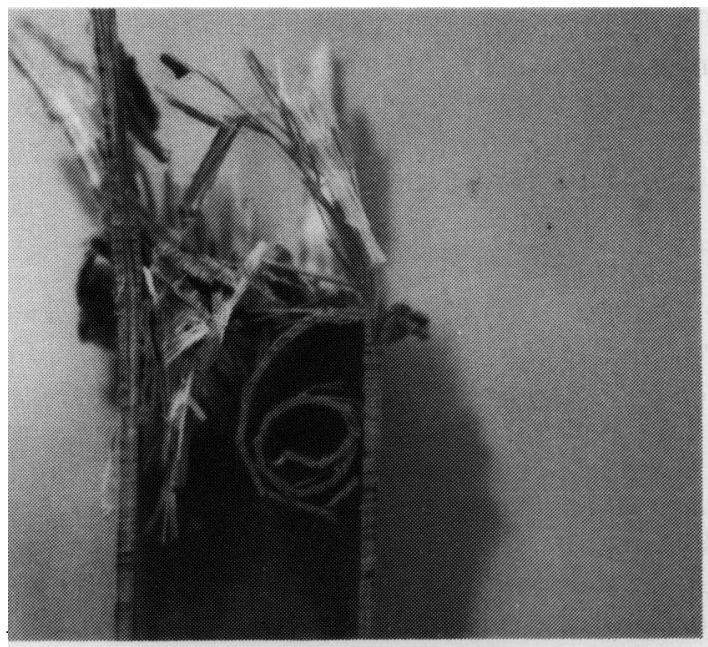

Figure 12. Specimen crushed by $10^{\circ}$ angled loading. 


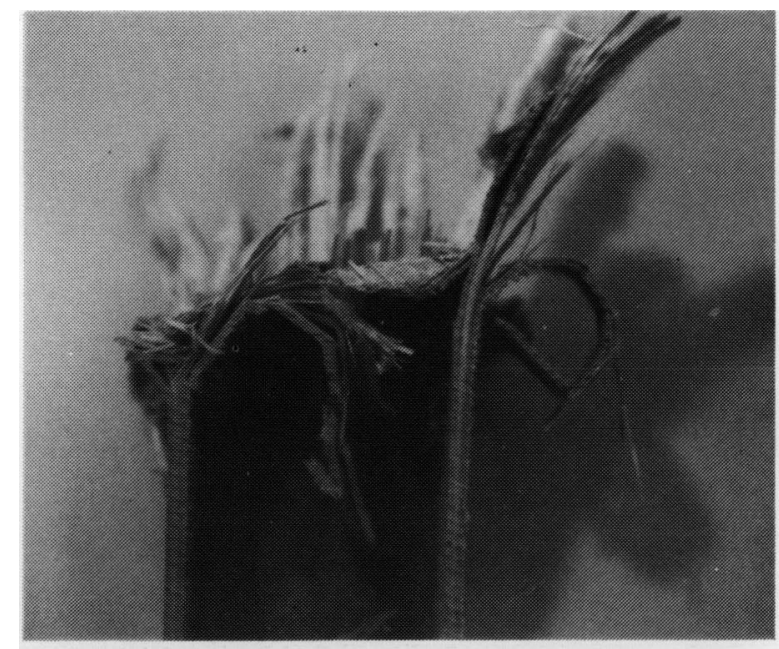

Figure 13. Specimen crushed by $10^{\circ}$ off-axis loading.

two types of loading were similar in both load magnitude and load constancy (variation in load).

Approximately $10 \mathrm{~g}$ of debris were created for specimens crushed using either of the non-axial loading configurations at the inclination angle of $10^{\circ}$, the same quantity found for axial loading. The nature of the debris, however, was somewhat different from axial loading. Proportionally more single fibers resulted from both types of non-axial loading. Most of the fibrous debris from axial loading is in the form of fiber bundles. For both loading configurations, the individual fibers that resulted were almost exclusively from the crushing of wall 1 . Compared to specimens crushed axially, the extent of fracture in specimens crushed at $10^{\circ}$ angled loading was increased in walls 2 and 3 , decreased in wall 4 , and approximately the same in wall 1 . The extent of fracture in off-axis loaded specimens was greater in wall 1, similar walls 2 and 3 , and less in wall 4 but still more than occurred than for angled loading (Figure 15).

\subsection{2 $15^{\circ}$ Crushing}

When crushed at $15^{\circ}$, wall 4 peels back, instead of crushing, for specimens loaded in both configurations. Examination after sectioning found wall 4 to be somewhat more cracked for off-axis loading. The way that wall 1 crushes is the primary difference between the two types of specimens (Figure 16). Angled loading results in the crushed material of wall 1 to splay to two sides, while off-axis loading results in material splaying to the inside only. The average distance between fracture lines was $4.7 \mathrm{~mm}$ for angled loading and $6.8 \mathrm{~mm}$ for off-axis loading, both slightly smaller than the corresponding values at $10^{\circ}$ loading.

The contour of the load-displacement curves produced became noticeably different at $15^{\circ}$ (Figure 17). Angled crushing produced a higher peak load (approx- 

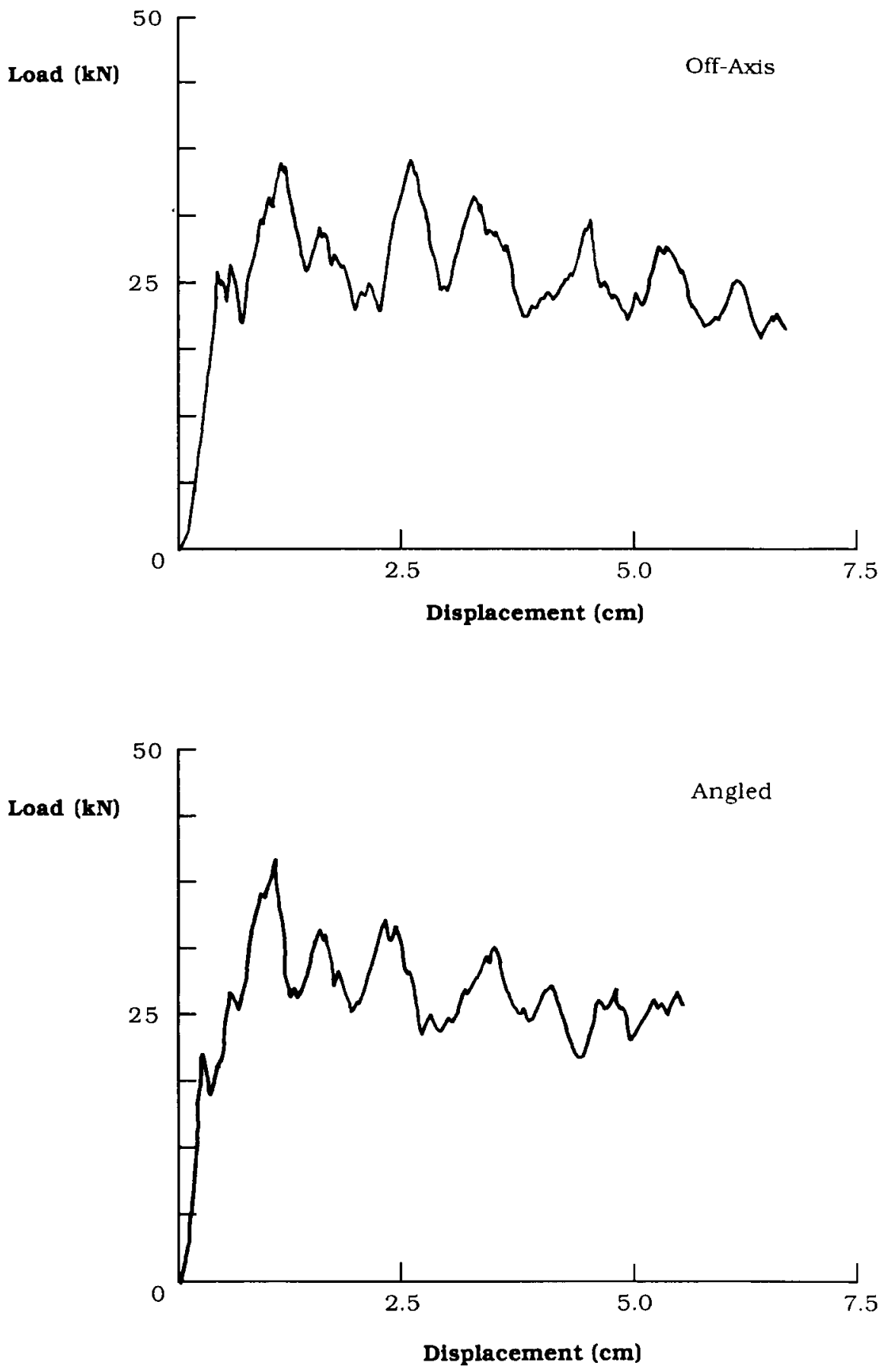

Figure 14. Load displacement curves for specimens crushed at $10^{\circ}$. 

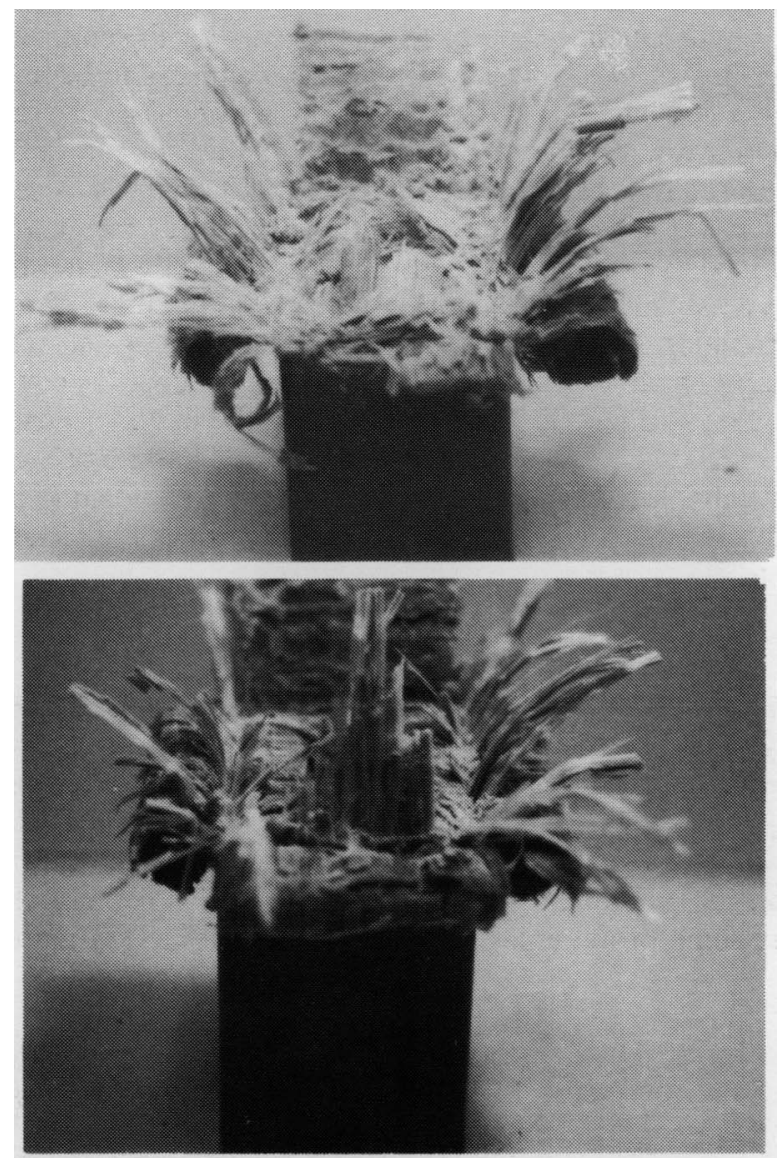

Figure 15. Tubes crushed by $10^{\circ}$ non-axial loading, off-axis on left.

imately $1000 \mathrm{lbs}$ ) and greater subsequent load constancy than off-axis crushing. Higher load constancy is generally associated with a smaller distance between fracture lines as was observed for walls 2 and 3 in angled loading. The peak load is produced when the crushing plate contacts wall 4 and the hoop reinforcement is broken. This was true also at higher angles of inclination for both loading configurations.

\subsection{3 $20^{\circ}$ Crushing}

Distinct differences in the observed crushing behavior occurred (as compared to the post crush specimen morphology) at $20^{\circ}$ crushing. The most prominent difference was in the crushing behavior of wall 1 (Figure 18). In off-axis loading, wall 1 clearly fails in bending. Bending failure initiates below the crushing sur- 
face (about $1 \mathrm{~cm}$ ) and can be seen when a whitened fracture line is created on the wall surface. Cyclic bending failure of wall 1 occurs for the entire crush distance. In angled loading, however, wall 1 fails in what appears to be a microbuckling process. The microbuckling occurs in such a way that the failed material cyclically alternates between splaying inward and splaying outward for the entire length of crushing. Eventually, all the material from wall 1 is forced to the inside of the tube because following a buckling cycle that causes the material to fail outward, another cycle occurs that forces the most recently fractured material inward. This is illustrated schematically in Figure 19. Another difference is that the depth of penetration of the corner cracks between wall 4 and walls 2 and 3 is noticeably larger in off-axis loading than in angled loading (Figure 20). This difference, however, is difficult to quantify because the depth of penetration of this crack increases as the crushing process proceeds. The separation between fracture lines of walls 2 and 3 averaged $7.3 \mathrm{~mm}$ in off-axis loading and $5.6 \mathrm{~mm}$ in angled loading. Again, the load was more constant for angled loading. as can be seen in Figure 21.

\subsection{4 $25^{\circ}$ Crushing}

At $25^{\circ}$, the specimen morphology and crush behavior were similar to $20^{\circ}$ crushing. Figure 22 shows longitudinally sectioned specimens crushed at $25^{\circ}$. A difference in the appearance of wall 1 can be noted from this cross-section. Offaxis crushing more completely fractures wall 1 at the fracture lines. Although the distinctness of the fracture lines is less for angled loading, the total amount of fracture in wall 1 is greater for angled loading. This is because the outside mat of wall 1 and some of the uniaxial fibers become debris during crushing. This

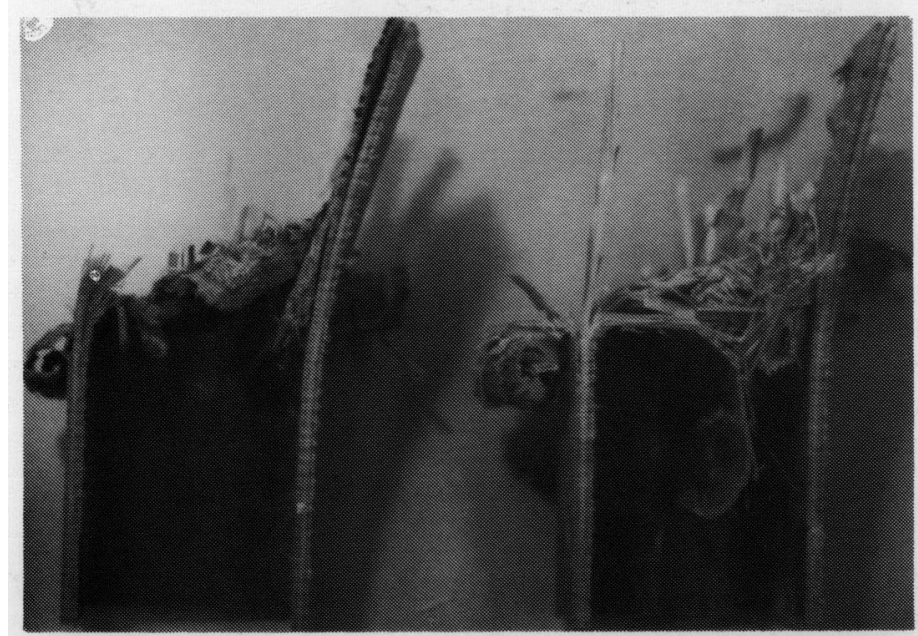

Figure 16. Longitudinal sections of specimens crushed at $15^{\circ}$ non-axial loading, off-axis on left. 

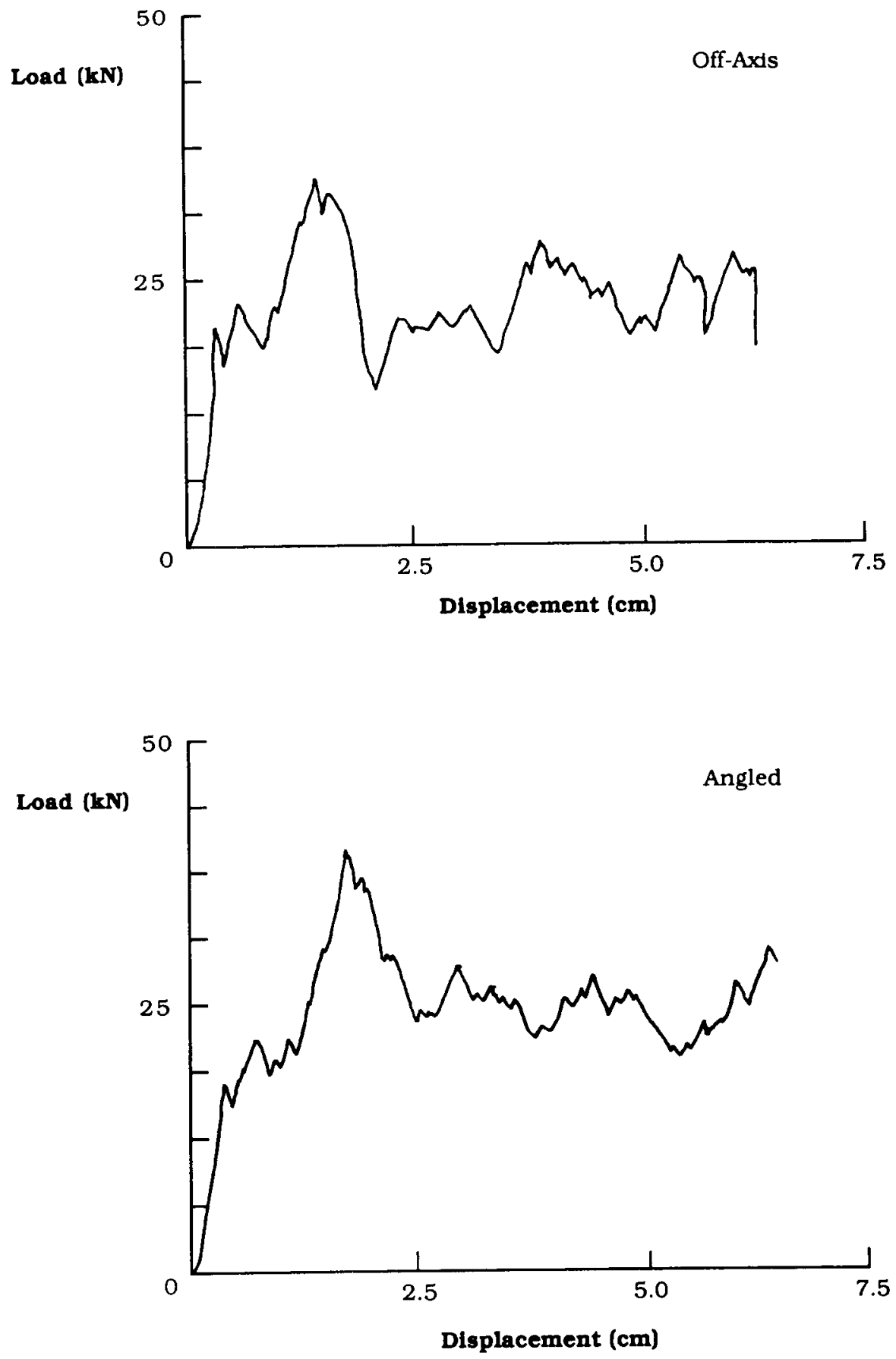

Figure 17. Load-displacement curves for specimens crushed at $15^{\circ}$ non-axial loading. 1092 


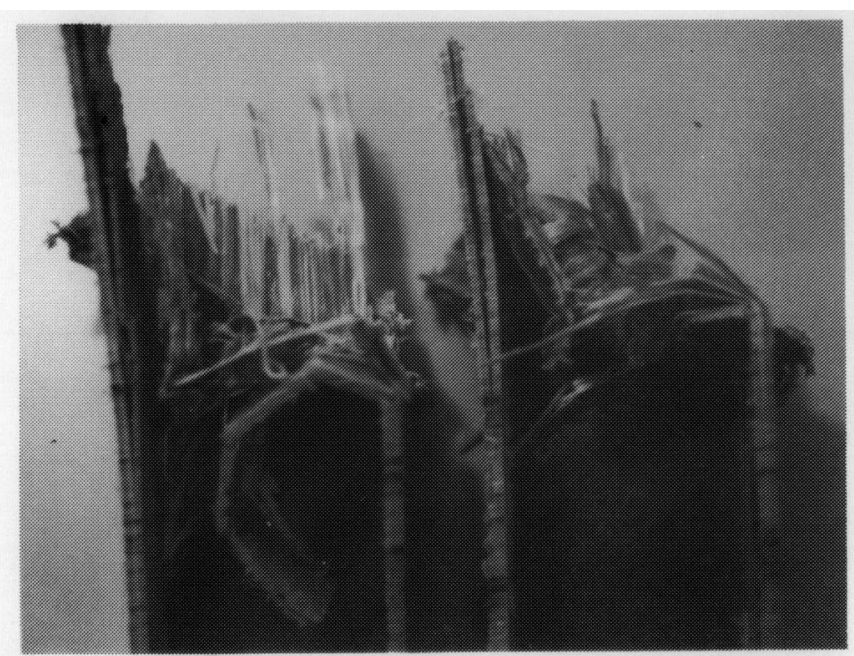

Figure 18. Longitudinal sections of specimens crushed at $20^{\circ}$ non-axial loading, off-axis on left.

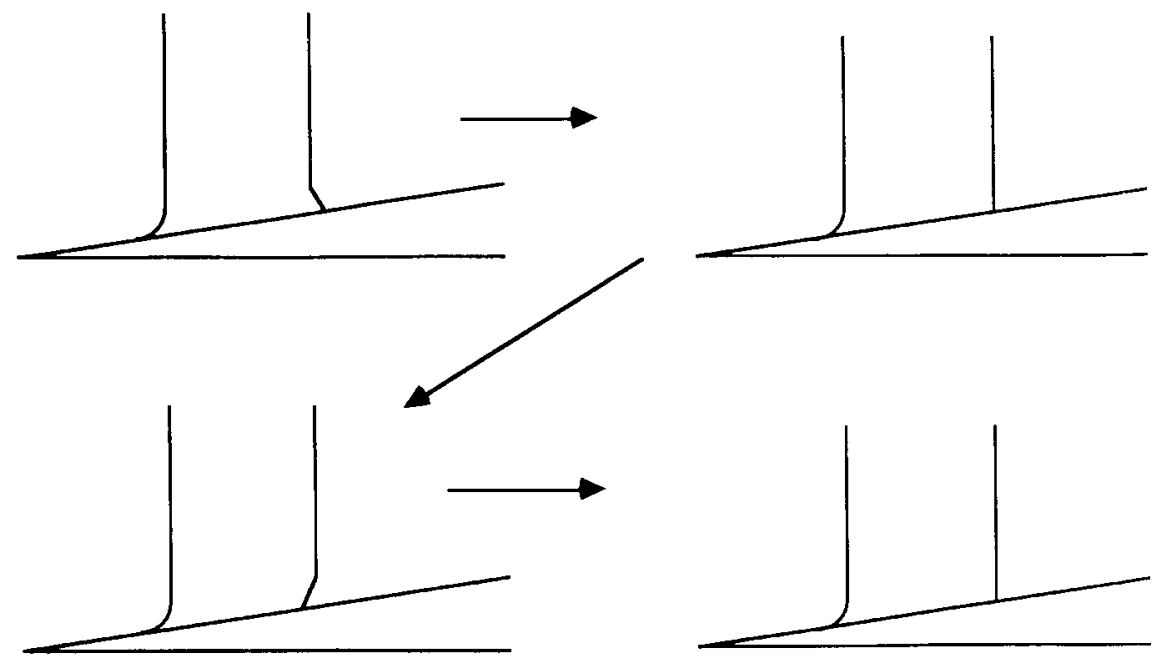

Figure 19. Cyclic crushing behavior of wall 1 by $20^{\circ}$ angled loading. 

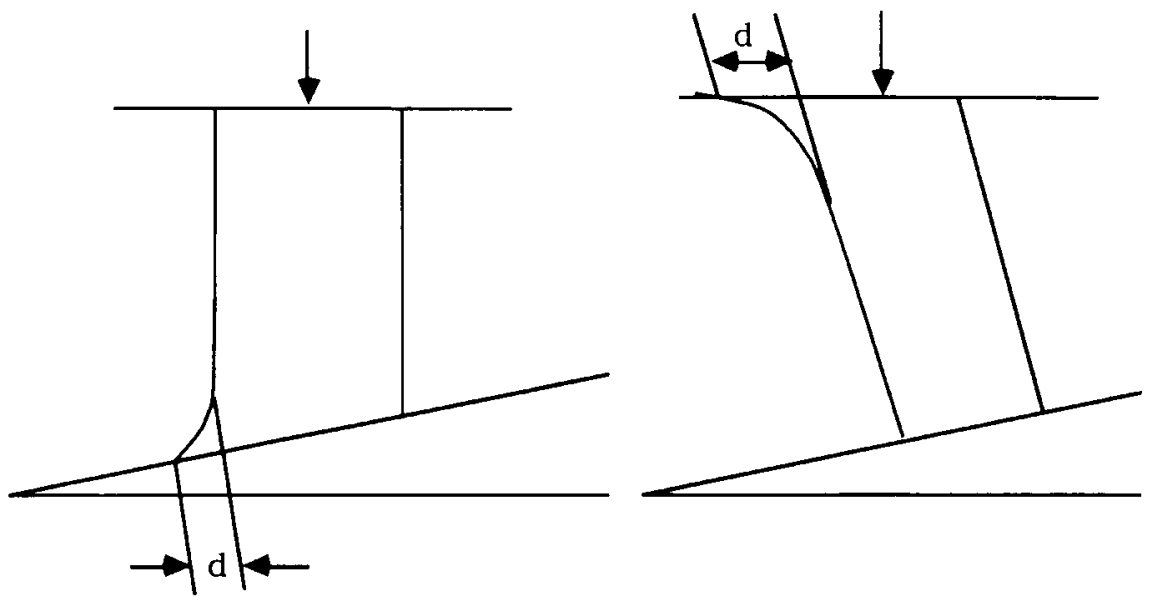

Figure 20. Relative wall peeling for non-axial loading at $20^{\circ}$.

debris is finer than the debris that is created in axial loading, consisting primarily of individual fibers and resin dust. An average amount of $10 \mathrm{~g}$ of debris resulted from angled loading but only $4 \mathrm{~g}$ from off-axis loading. This difference can be accounted for by a larger amount of fracture in wall 1 in angled loading than offaxis.

Crushing at $25^{\circ}$ angled loading also produced a cyclical microbuckling failure in wall 1 . Off-axis loading produced a series of bending failures as seen at $20^{\circ}$. The corner cracks produced between wall 4 and the two side walls were again deeper for off-axis loading than angled loading.

The average fracture line separation distance was $5.7 \mathrm{~mm}$ for angled loading and $8.2 \mathrm{~mm}$ for off-axis loading. The differences in the load-displacement curves were similarly large, with the peak load about $2000 \mathrm{lbs}$ higher for angled loading than off-axis. The load constancy was greater for angled loading although it was not good for either non-axial loading configuration (Figure 23).

\section{DISCUSSION}

Axial crushing of E-glass/polyester tubes and E-glass/vinyl ester tubes [11] has shown that certain parameters must be controlled for crushing to proceed satisfactorily. Of primary importance is the control of crack behavior. Crack behavior appears to depend upon the arrangement of fibers and the geometry of the specimen. The reinforcement of the polymer with fibers is in fact essential for satisfactory energy absorption. The fibers act as sites for crack initiation and direct the crack propagation as well. In unreinforced polymers such as vinyl ester resin, cracks initiated by triggering are not directed and generally terminate on the side surface of the structure [12]. When cracks terminate at the surface, crack regeneration does not occur and the stable crushing process ceases. Not only are 

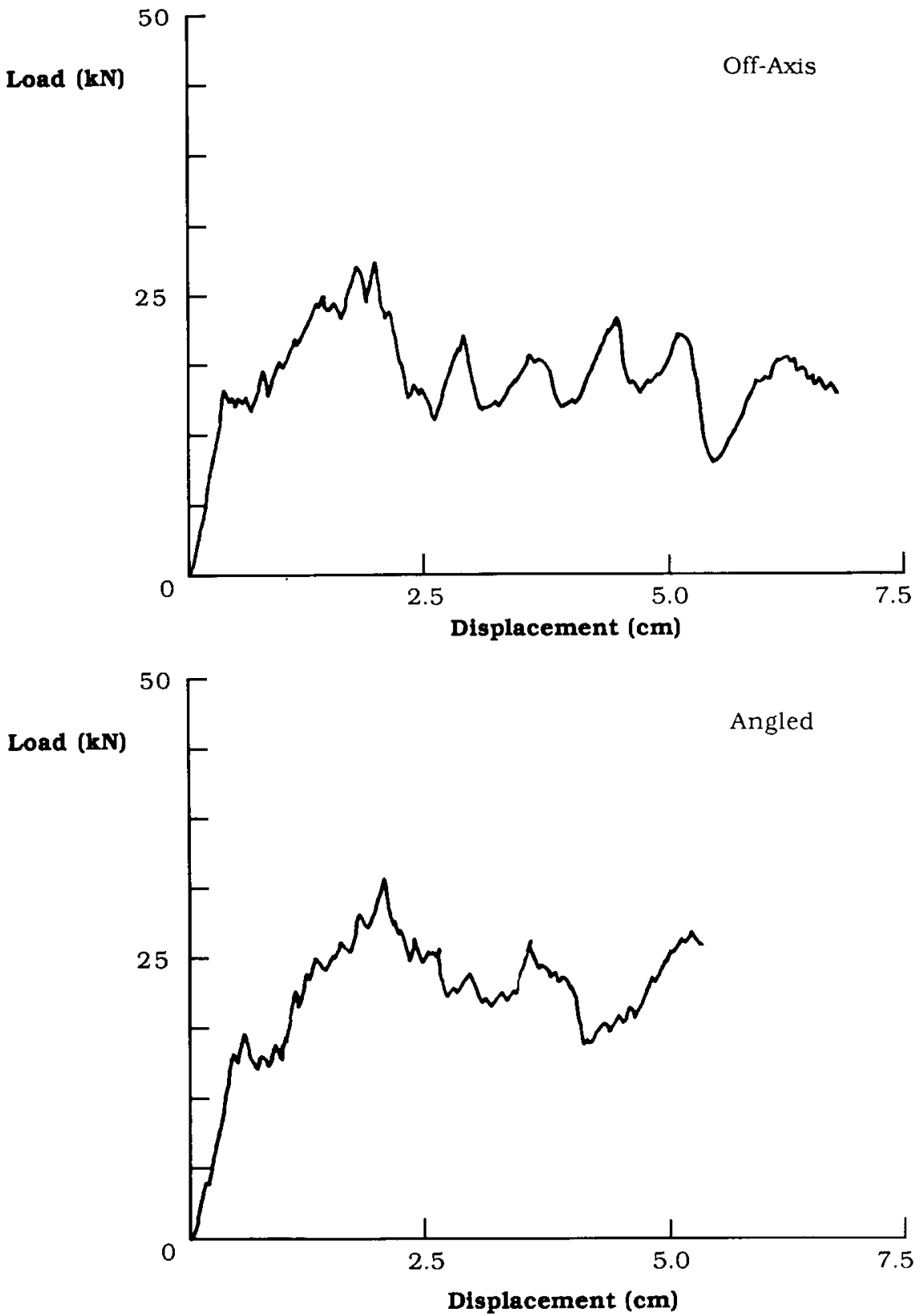

Figure 21. Load-displacement curves for $20^{\circ}$ non-axial loading. 


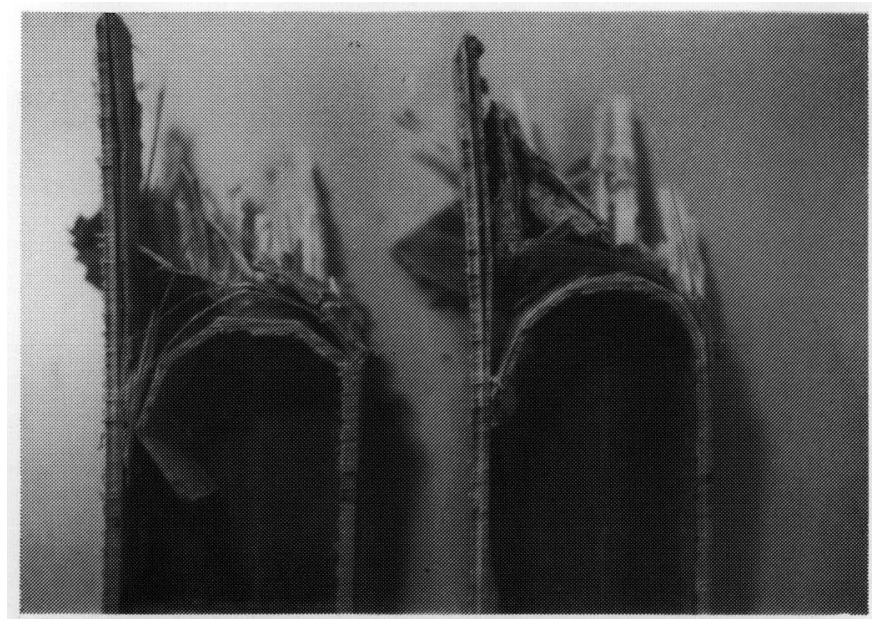

Figure 22. Longitudinal sections of specimens crushed at $25^{\circ}$ non-axial loading, off-axis on left.

cracks necessary, but it appears that a sufficient density of cracks must exist for the crush process to proceed in a stable manner.

Another important parameter is the depth of crack penetration which apparently influences strongly the load supportable by the crush zone [11]. For pultrusions, the depth of crack penetration, or more specifically, the depth of delamination between the glass mats and the uniaxial fibers, is related to the distance between the fracture lines. This distance is approximately equal to the crack penetration depth. From this and other work $[10]$, the depth of crack penetration appears to be dependent upon at least three factors: structure geometry, the material, and the triggering method. For this study, all three of these parameters were held constant. However, it can be argued that as the angle of inclination of the tube was changed, the tubes were triggered differently. This was true for the bevel trigger and is probably valid for other types of triggers also.

The type of triggering affects the magnitude of energy absorption as well as the failure mode $[8,10]$. The initiation part of the crush process is important because once started, the type of failure that is initiated persists for the entire crush process. For example, in vinyl ester pultrusions, differences in triggering have been found to alter the energy absorption by up to $100 \%[10]$. The primary visible difference in the appearance of the crushed pultrusions from the two types of loading was the distance between fracture lines. This would indicate that at least one of the causes for change in energy absorption for alternative trigger modes is the depth of crack penetration or depth of delamination. Other alterations may have occurred with the change in triggering method but were less obvious. Thus it appears that the changes in energy absorption may have, at least in part, been due to the altered triggering that resulted and the consequent different depth of delamination. Since each of the wall sections was loaded differently and presum- 

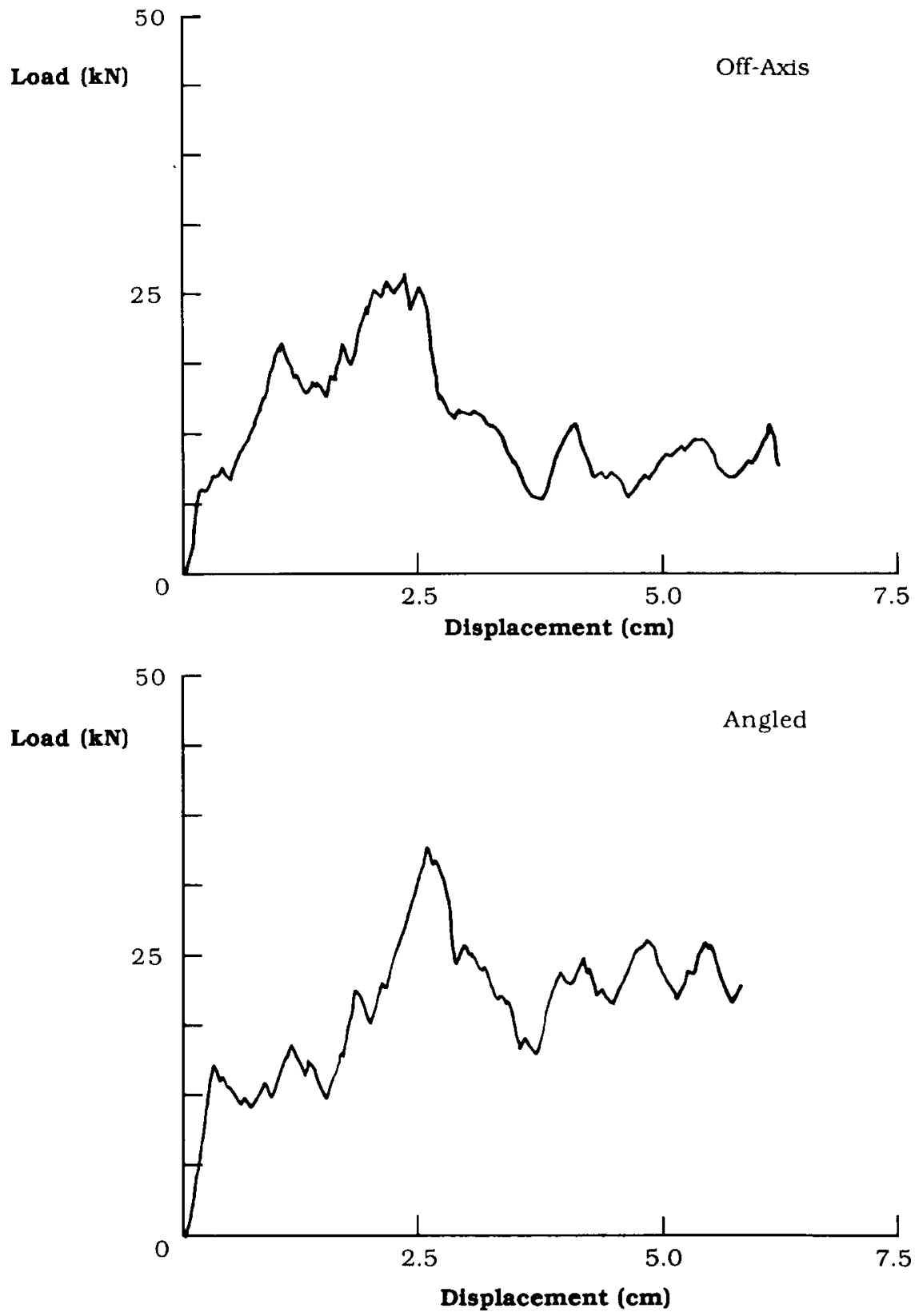

Figure 23. Load-displacement curves for specimens crushed at $25^{\circ}$ non-axial loading. 
ably triggered differently, the depth of delamination was not identical for each of the wall segments.

The change in response that occurs when an alternative trigger is used in axial loading, as opposed to when a tube is triggered differently by non-axial loading, is that the crack penetration depth differs among triggers but is the same for each of the wall sections loaded. When the angle of inclination is changed but the trigger geometry is unchanged, the fracture band distance and, presumably crack penetration distance, is not uniform for all wall segments. This would indicate that three of the four segments had altered triggering and consequently absorbed energy differently.

One factor that is consistent throughout testing is that wall 4 is loaded differently for off-axis loading than for angled loading. Although this is certainly true to some extent for the other walls, the change in the loading of wall 4 seems greater. Regardless of the angle of inclination, a transverse loading component is applied to wall 4 . Although a transverse load is applied to wall 4 also in angled loading, friction acts to reduce the magnitude of this component. Therefore, a larger stress is applied to the hoop fibers in off-axis loading than in angled loading for a comparable angle of inclination. By causing earlier fracture of the hoop fibers, the stability of the crush zone in off-axis loading is reduced.

The process of energy absorption can be viewed as one in which the crush load is supported by a number of independent structural elements. When one of the elements fails, its load must be transferred to another structural element. This switching of load support can be imagined to occur among two or more independent structural elements as the crushing process continues. This crush load would then generally reflect the load that is supported by the weakest structural element operative. If, as for non-axial loading, one of the structural elements that supports the load is the tube corners, which is dependent upon the hoop reinforcement structure, then a higher stress level induced in the hoop reinforcement fibers by a given loading situation would cause the overall load carrying ability of the structure to be lower. This is perhaps one of the operating mechanisms that produces lower load levels for off-axis than for angled loading.

Although it is fairly certain that the depth of delamination is largely responsible for energy absorption changes, it is less certain why the depth of delamination changes. One possible reason is that as the testing angle is changed, cracks are forced to take different paths which have varying degrees of difficulty for penetration. Once a certain path has been taken there is the tendency for the crack to continue along that path. Thus, crack penetration is relatively easier or more difficult depending on the type of cracking produced initially.

A contrast exists between the two loading conditions in the way the individual fibers are loaded. If the fibers can be considered to be loaded as shown in Figure 24 , changes in energy absorption levels may result because of different interactions of the individual fibers with the asperities on the crushing plate. The loading of the fibers in angled loading can be assumed to be very similar to axial loading. That is, the fibers in angled loading would likely fail by buckling but by bending in off-axis loading. Also, although it could not be confirmed from the crush morphology microscopically, crack propagation may be different for the 

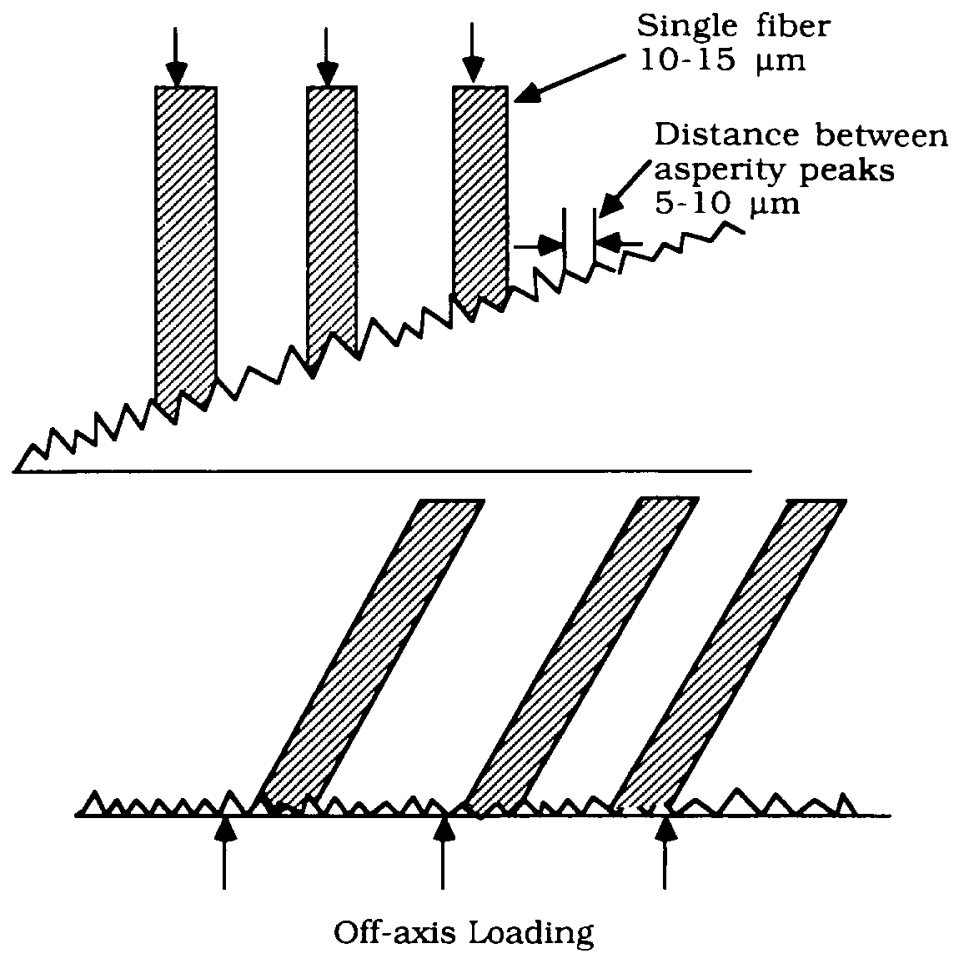

Figure 24. Loading of individual fibers.

two loading conditions. Angled loading would produce a situation where the cracks propagate in more of a pure mode I fashion and mixed modes I and II in off-axis.

It is difficult to determine precisely all the mechanisms that produce the crushing behavior differences between off-axis and angled loading. A number of mechanisms are likely to be operative, and some may act in opposition. For example, off-axis and angled loading both were observed to produce load levels higher than for axial loading. This is a curious result because for angled loading, in particular, wall 4 is nearly undamaged. However, it was determined that the distance between fracture lines was shorter for walls 2 and 3 than occurs in axial loading. It is known that decreasing the distance between fracture lines has a positive effect on the load level produced during crushing [12]. It is probable that by nearly eliminating the damage induced in wall 4 , the level of energy absorption tends to be reduced. The reduction in the distance between fracture lines, and perhaps other factors, seems to compensate for the inefficient crushing in wall 4 .

\section{CONCLUSION}

Provided global failure does not occur, the tubes studied can absorb energy sat- 
isfactorily in non-axial loading. But the energy absorption behavior found for two types of non-axial loading, angled and off-axis loading, can be very different. Angled loading occurs when a vehicle moving forward along its longitudinal axis impacts an object tilted away from being perpendicular to the vehicle's longitudinal axis; off-axis loading occurs when a spinning vehicle impacts an object from a direction not along its longitudinal axis. The disparity in behavior between angled and off-axis loading results from differences in the friction between the tube and the crushing plate. Off-axis loading involves a dynamic type of friction, and angled loading a static type. The result is that less energy is absorbed generally in off-axis than in angled loading. In addition to the differences between offaxis and angled loading, specimens crushed under each behaved differently at different loading angles. This seemed to be due, in part at least, to the change in the crack initiation pattern with angle of inclination. Whatever crack pattern is initiated tends to remain the same as the entire tube is crushed.

\section{ACKNOWLEDGEMENT}

Michael J. Czaplicki and Richard E. Robertson wish to acknowledge financial support from the Ford Motor Company during the course of this work.

\section{REFERENCES}

1. Farley, G. L. 1987. "Energy Absorption of Composite Material and Structure," American Helicopter Society Forum and Technology Display.

2. Bannerman, D. C. and C. M. Kindervator. 1987. "Crash Impact Behavior of Simulated Composite Fuselage Elements," Ninth European Rolorcruft Forum.

3. Thornton, P. H., J. J. Harwood and P. Beardmore. 1985. "Fiber Reinforced Plastic Composites for Energy Absorption Purposes," Compos. Sci. Tech., 24:275-298.

4. Thornton, P. H. and P. J. Edwards. 1982. "Energy Absorption in Composite Tubes," J. Compos. Mater., 16:521-545.

5. Beardmore, P., C. F. Johnson and G. G. Strosberg. 1987. "Impact of New Materials on Basic Manufacturing Industries, Case Study: Composite Automotive Structure," OTA. Contract No. 633-4975.0.

6. Bcardmore. P. and C. F. Johnson. 1986. "The Potential of Composites in Structural Automotive Applications," Compos. Sci. Tech., 26:251-281.

7. Reid, S. R. and T. Y. Reddy. 1986. "Static and Dynamic Crushing of Tapered Sheet Metal Tubes of Rectangular Cross-Section," J. Mech. Sci., 28(9):623-637.

8. Thornton, P. H. 1985. "Effect of Trigger Geometry on Energy Absorption of Composite Tubes," ICCM-V, Harrington. Strife, and Dhingra, eds.. Pennsylvania: Metallurgical Society, pp. 1183-1199.

9. Thornton, P. H. 1979. "Energy Absorption in Composite Structures," J. Compos. Mater., 13: 247-262.

10. Craplicki, M. J., R. E. Robertson and P. H. Thornton. 1988. "Triggering of Polymer Composite Tubes," ASM-ESD, Detroit, MI: Advanced Composites, pp. 39-46.

11. Czaplicki, M. J. R. E. Robertson and P. H. Thornton. 1989. "Comparison of Bevel and Tulip Triggered Tubes." Compos. Sci. Technol., in press.

12. Tao, W. 1988. University of Michigan. Unpublished research.

13. Price, J. N. and D. Hull. 1987. "Axial Crushing of Glass-Polyester Composite Cones," Compos. Sci. and Tech., 28:211-230. 